\title{
Nano-Structured Cu/W Brazing Fillers for Advanced
}

\section{Joining Applications}

Frank Moszner ${ }^{1}$, Claudia Cancellieri ${ }^{1 *}$, Christoph Becker ${ }^{2}$, Mirco Chiodi ${ }^{1}$, Jolanta Janczak-Rusch ${ }^{1}$ and Lars P. H. Jeurgens ${ }^{1}$

1. Empa, Swiss Federal Laboratories for Materials Science and Technology, Überlandstrasse 129, CH-8600 Dübendorf, Switzerland

2. Institute of Virtual Manufacturing (IvP), ETH Zurich, Tannenstrasse 3, CH-8092 Zurich, Switzerland

\begin{abstract}
Nano-multilayered brazing fillers offer a high potential for joining heat sensitive materials at reduced temperatures. In the current work $\mathrm{Cu} / \mathrm{W}$ based nano-multilayered coatings, fabricated via physical vapor deposition (PVD) are studied. Joints were successfully produced via deformation dilatometry at temperature of $750{ }^{\circ} \mathrm{C}$ and a mechanism for the bonding process is suggested. The promising results indicate an attractive pathway for using the versatile ability of PVD to precisely control the microstructure on the nm-scale and enabling tunable joint properties.
\end{abstract}

Key words: Microstructure, joining, brazing, nano-structures, $\mathrm{Cu} / \mathrm{W}$ nano-multilayers, thin films.

\section{Introduction}

Modern brazing technology increasingly faces the problem of joining heat sensitive materials without altering their often highly optimized microstructure (and the thus related material properties) by the bonding process $[1,2]$. To meet these requirements, the joining process should be carried out at ever reduced temperatures and/or times. In conventional brazing the melting point of the brazing filler determines the lowest suitable joining temperature. The traditional approach to reduce the process temperature is based on the survey of low melting point alloys such as deep eutectic systems. Joining using nano-multilayer (NML) based brazing fillers has been shown to be a promising route for low-temperature joining applications $[1,3,4]$. The basic concept of this approach is to exploit nano-scale effects such as (i) the size dependency of the melting point and (ii) the high density of internal interfaces (e.g. grain boundaries, inter phase boundaries) of nano-structured materials to tailor both of the

*Corresponding author: Claudia Cancellieri, research scientist, research fields: nanomultilayers, oxides, stress and structural properties. thermodynamics (temperature) [5-7] and the kinetics (time) $[4,8]$ of the joining process. The NML brazing fillers are composed of alternating nanolayers (individual thickness $\leq 10 \mathrm{~nm}$ ) of a metal (or alloy) and a chemically-inert barrier (e.g. oxides, nitrides or refractory metals). So far, mainly metal/ceramic systems have been investigated such as $\mathrm{Cu} / \mathrm{AlN}$ [3], $\mathrm{Ag} / \mathrm{AlN}$ [9] and $\mathrm{Ag}-\mathrm{Cu} / \mathrm{AlN}[10,11]$. However, the choice of a refractory metal, such as $\mathrm{W}$, Mo or Ta, as inert barrier has not yet been considered in much detail. The $\mathrm{Cu}-\mathrm{W}$ system fulfills most criteria for the design of a NML brazing fillers: i.e. the constituents are immiscible, and according to the binary phase diagram, no solid state phase transformations occur up to the $\mathrm{Cu}$ melting point [12]. In addition, due to their interesting thermal and mechanical properties, $\mathrm{Cu} / \mathrm{W}$ thin films and $\mathrm{Cu} / \mathrm{W}$ multilayered coatings have attracted great attention both from a scientific and technological perspective [13-15].

In the current work, the feasibility of a $\mathrm{Cu} / \mathrm{W}$ based NML coating, as produced by conventional magnetron sputtering for joining applications, is evaluated. Deformation dilatometry is used to perform joining experiments under controlled processing conditions, 
i.e. fixing force, temperature profile and atmosphere. Specimens in the as deposited state and after joining are analyzed using X-ray diffraction (XRD) and high resolution scanning electron microscopy (HR-SEM).

\section{Experimental}

The following two thin films were investigated: (i) pure $\mathrm{Cu}$, with a thickness of $1 \mu \mathrm{m}$ and (ii) $\mathrm{Cu} / \mathrm{W}$ NML, where first a $25 \mathrm{~nm}$-thick $\mathrm{W}$ buffer layer was deposited on the substrate followed by 100 repetitions of alternating $\mathrm{Cu}$ and $\mathrm{W}$ layers with an individual thickness of $5 \mathrm{~nm}$, denoted as $\mathrm{W}_{25 \mathrm{~nm}}+\left(\mathrm{Cu}_{5 \mathrm{~nm}} / \mathrm{W}_{5 \mathrm{~nm}}\right) \times$ 100. The coatings were deposited on polished (down to $1 \mu \mathrm{m}$ diamond size) molybdenum blocks (99.97 purity, Plansee, Austria), having a size of $25 \times 25 \times 5$ $\mathrm{mm}^{3}$, by using magnetron sputtering in a high vacuum chamber (base pressure $<10^{-8}$ mbar) from two confocally arranged, unbalanced magnetrons equipped with 2" targets of pure $\mathrm{W}(99.95 \%)$ and pure $\mathrm{Cu}$ (99.99\%). For the joining experiments cubes having a size of $5 \times 5 \times 5 \mathrm{~mm}^{3}$ were cut from the bigger coated blocks via spark erosion.

Fig. 1 gives a detailed overview on the joining experiments performed by means of a DIL $805 \mathrm{~A} / \mathrm{D} / \mathrm{T}$ deformation dilatometer (Baehr, Germany) provided by the IvP from the ETH Zurich. Joining was performed under vacuum $\left(<10^{-4} \mathrm{mbar}\right)$ at $750^{\circ} \mathrm{C}$ for a dwell time of $100 \mathrm{~min}$ and an applied fixing force of $1,250 \mathrm{~N}$, which correlates to $50 \mathrm{MPa}$ considering the cube surface area of $25 \mathrm{~mm}^{2}$.

HR-SEM analysis was performed using a Hitachi S-4800 (Hitachi High-Technologies Corporation, Japan) instrument equipped with a Bruker XFlash 6|60 energy dispersive X-ray (EDX, Bruker, Germany) detector. Cross-sectional cuts were prepared by using a Hitachi IM4000 $\mathrm{Ar}^{+}$ion milling system applying an acceleration voltage of $6 \mathrm{kV}$, a discharge voltage of $1.5 \mathrm{kV}$ and a swing angle of $\pm 30^{\circ}$. Prior performing the cross-sectional cuts of the samples in the as deposited state an Au coating was deposited on-top of the specimens in order to protect the surface from possible contaminations/alterations.

XRD measurements (Discover D8, Bruker, Germany) in the $2 \theta$ range of $20^{\circ}-90^{\circ}$ were conducted using $\mathrm{CuK \alpha}_{1,2}$ radiation operated at $40 \mathrm{kV}$ and $40 \mathrm{~mA}$.

\section{Results and Discussion}

Fig. 2 displays HR-SEM images of cross-sectional cuts and XRD-patterns of the coatings (with equal total thickness) in the deposited state. No indications of cracks, voids or delamination are apparent. For the $\mathrm{Cu}$ coating (Fig. 2a) a homogenous film with a polycrystalline grain structure can be observed. In the case of the $\mathrm{Cu} / \mathrm{W}$ NML (Fig. 2b) the $25 \mathrm{~nm}$-thick W
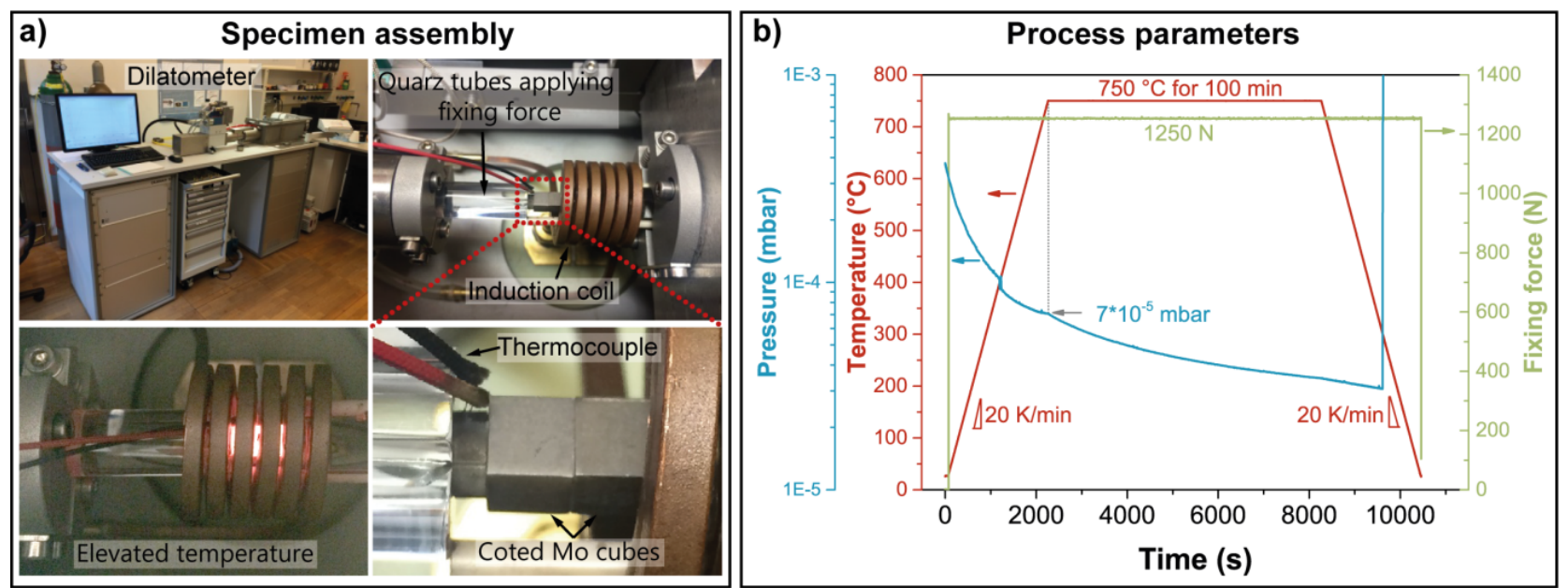

Fig. 1 Details on the joining process: (a) deformation dilatometer and assembly of the samples. The temperature was measured by means of a chromel-alumel thermocouple spot-welded to cylindrical Mo-part located on the left hand side of the cubes and (b) process parameters, i.e. chamber pressure, temperature and applied fixing force. 

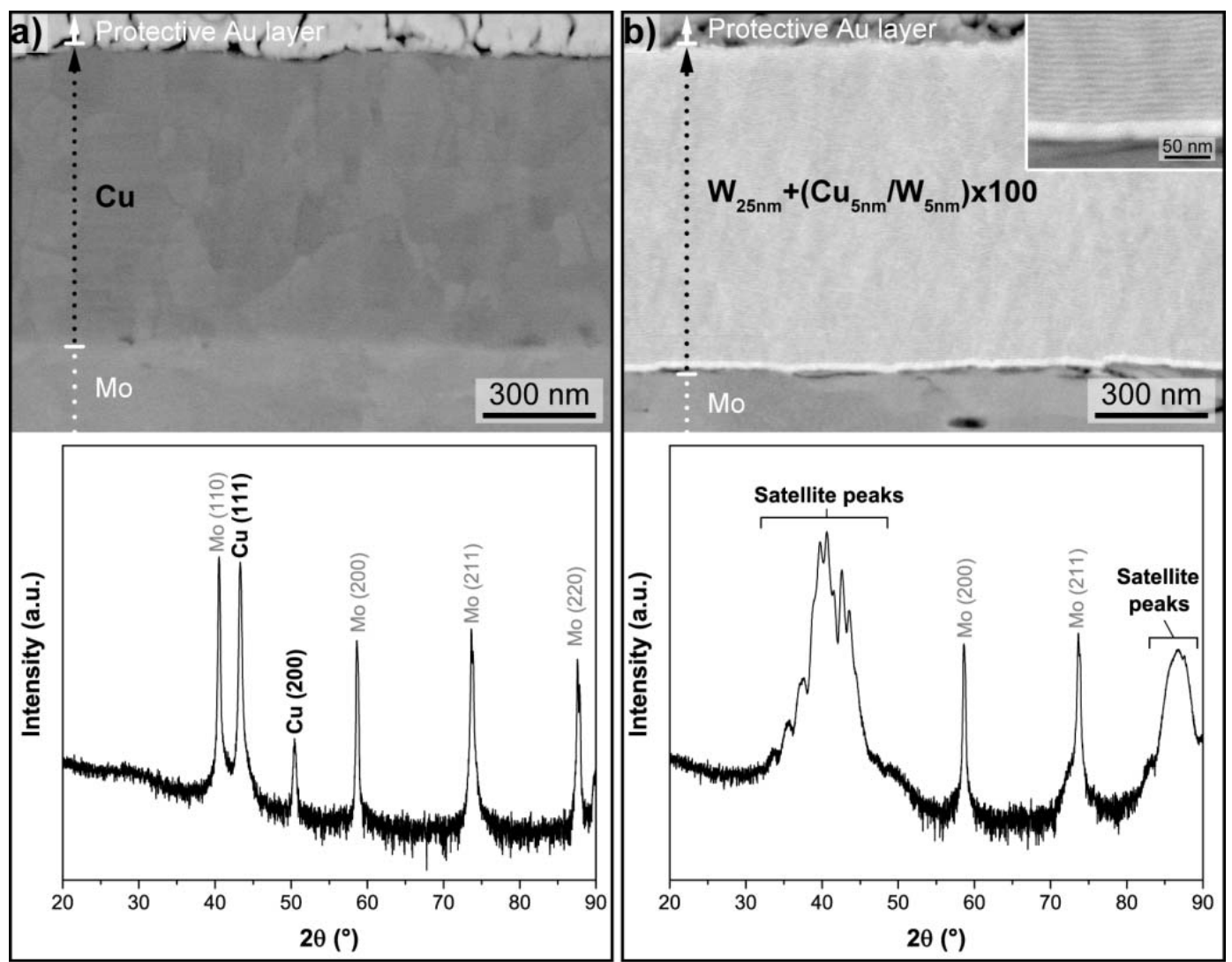

Fig. 2 Cross-sections and XRD-patterns of the of the coatings in the as-deposited state of (a) Cu coating and (b) $\mathrm{W}_{25 \mathrm{~nm}}+$ $\left(\mathrm{Cu}_{5 \mathrm{~nm}} / \mathbf{W}_{5 \mathrm{~nm}}\right) \times 100$.

buffer layer and the periodicity of the alternating $\mathrm{Cu} / \mathrm{W}$ nanolayers is resolved (inset Fig. 2b). In the XRD spectra of the $\mathrm{Cu}$ coating (Fig 2a) fcc diffraction lines, indicating a polycrystalline thin film as well as bcc reflections related to the Mo substrate are visible. For the $\mathrm{Cu} / \mathrm{W}$ NML (Fig. 2b), besides the Mo-substrate diffraction lines, well-defined satellite peaks of $\mathrm{Cu}(111)$ and $\mathrm{W}(110)$ are revealed in the $2 \theta$ range from $30^{\circ}$ to $48^{\circ}$, which are characteristic for oriented alternating nanolayered systems (e.g. [16]).

Fig. 3 displays cross-sectional HR-SEM images of both specimens after joining at $750{ }^{\circ} \mathrm{C}$ using the deformation dilatometer. For the $\mathrm{Cu}$ coated sample (Fig. 3a), a sound joint is revealed with coarsened $\mathrm{Cu}$ grains which partly extend over the entire joining zone. Diffusion bonding of PVD-based $\mathrm{Cu}$ thin films has been demonstrated for temperature $350-400{ }^{\circ} \mathrm{C}$ [17]. Analogously, for the joining using the $\mathrm{Cu}$ coating, a bonding mechanism based on the interdiffusion of $\mathrm{Cu}$ atoms as well as grain growth can be assumed. For $\mathrm{W}_{25 \mathrm{~nm}}+\left(\mathrm{Cu}_{5 \mathrm{~nm}} / \mathrm{W}_{5 \mathrm{~nm}}\right) \times 100$ (Fig. 3b) small pores (white arrows) and interestingly accumulations of $\mathrm{Cu}$ (black arrows) are observable at the bond interface, i.e. between the initial surfaces (W outermost layer) of the coating. Thus indicating that during heating Cumust have penetrated through the $\mathrm{W}$ layers to the top. Furthermore, the initial nanolayered structure has degraded towards a spheroidized nanocomposite (cf. insert of Figs. $2 \mathrm{~b}$ and $3 \mathrm{~b}$ ). The microstructural evolution upon heating of the same $\mathrm{Cu} / \mathrm{W}$ NML system (deposited on sapphire) has been studied in detail [18] and the corresponding stress evolution was comprehensively investigated [19]. As shown by these studies, in the as deposited state very high compressive stresses (related mainly to growth stresses initiate by the PVD process) were observed in the confined $\mathrm{Cu}(\approx-1.5 \mathrm{GPa})$ and $\mathrm{W}$ layers $(\approx-3.5 \mathrm{GPa})[19]$. Annealing up to $500{ }^{\circ} \mathrm{C}$ fully releases 

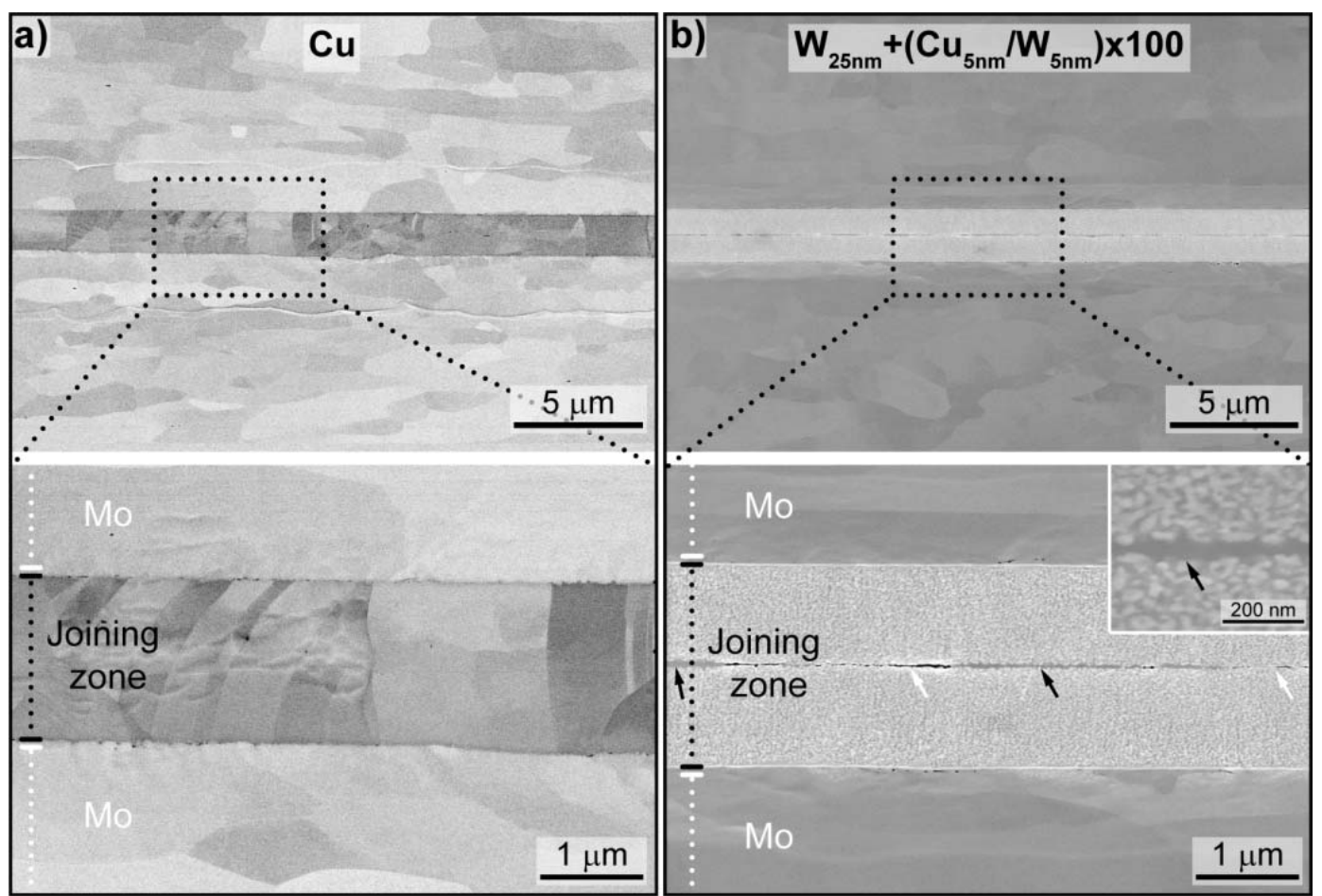

Fig. 3 HR-SEM images of cross-section after joining (a) Cu coating, (b) $\mathrm{W}_{25 \mathrm{~nm}}+\left(\mathrm{Cu}_{5 \mathrm{~nm}} / \mathrm{W}_{5 \mathrm{~nm}}\right) \times 100$.

the stresses of the $\mathrm{Cu}$ nanolayers [19], which also coincides with the temperature at which a high number of $\mathrm{Cu}$ protrusions appear on the surface [18]. At $\mathrm{T}>700{ }^{\circ} \mathrm{C}$, degradation of the NML structure occurs $[18,19]$. Consequently, it is suggested for $\mathrm{W}_{25 \mathrm{~nm}}+\left(\mathrm{Cu}_{5 \mathrm{~nm}} / \mathrm{W}_{5 \mathrm{~nm}}\right) \times 100$ that upon heating $(>500$ $\left.{ }^{\circ} \mathrm{C}\right) \mathrm{Cu}$ penetrates through the $\mathrm{W}$ layers to the bond interface. $\mathrm{Cu}-\mathrm{Cu}$ bonding is established similar to the diffusion bonding process seen for the pure $\mathrm{Cu}$ sample. Subsequently degradation of the NML structure $\left(>700^{\circ} \mathrm{C}\right)$ by thermal grooving occurs (more details in Ref. [18]). Here it is emphasized that such $\mathrm{Cu} / \mathrm{W}$ nano-composite structures can be very attractive for applications, where a combination of good thermal- and electrical conductivity with high mechanical properties is required. For example, $\mathrm{Cu}$-rich $\mathrm{Cu} / \mathrm{W}$ pseudo alloys, where $\mathrm{W}$ acts as hardening phase, show superior mechanical properties (e.g. high strength, better creep resistance) compared to pure $\mathrm{Cu}$ while still offering a very high electrical and thermal conductivity. Functional grades $\mathrm{Cu} / \mathrm{W}$ composites can also be used to accommodate differences in thermal expansion coefficients. In this regard, combining the versatile properties of $\mathrm{Cu} / \mathrm{W}$ composites with the possibility of magnetron sputering to precisely control the microstructure on a $\mathrm{nm}$-scale, tunable joint properties can be envisaged. Motivated by these very promising results further investigations will be performed to study the influence of the joining process parameters, as well as to evaluate the mechanical performance of the joints.

\section{Conclusions}

$\mathrm{Cu} / \mathrm{W}$ based nano-multilayered brazing fillers were successfully employed to fabricate joints at temperature of $750^{\circ} \mathrm{C}$. A joining zone comprising of a spheroidized $\mathrm{Cu} / \mathrm{W}$ nanocomposite and accumulation of $\mathrm{Cu}$ at the bond interface results. According to recent studies, it is suggested that upon heating $\mathrm{Cu}$ penetrates the $\mathrm{W}$ barrier layers $\left(>500{ }^{\circ} \mathrm{C}\right)$ and migrates to the bond interface. $\mathrm{Cu}-\mathrm{Cu}$ bonds similar as in a diffusion bonding process are established. Furthermore the initial NML structure degrades to a spheroidized nanocomposite $\left(>700{ }^{\circ} \mathrm{C}\right)$. The results 
indicate an attractive and versatile approach for tailorable joint properties.

\section{Acknowledgment}

The Empa laboratory for reliability science and technology is acknowledged for the provision of the scanning electron microscope.

\section{References}

[1] Janczak-Rusch, J., Kaptay, G. and Jeurgens, L. P. H. 2014. "Interfacial Design for Joining Technologies: An Historical Perspective." Journal of Materials Engineering and Performance 23 (5): 1608-13.

[2] Zhou, Y., M. 2008. Microjoining and Nanojoining. Woodhead Publishing.

[3] Lehmert, B., Janczak-Rusch, J., Pigozzi, G., Zuraw, P., Mattina, F. L. and Wojarski, L. et al. 2015. "Copper-Based Nanostructured Coatings for Low-Temperature Brazing Applications." MATERIALS TRANSACTIONS 56 (7): 1015-8.

[4] Kaptay, G., Janczak-Rusch, J. and Jeurgens, L. P. H. 2016. "Melting Point Depression and Fast Diffusion in Nanostructured Brazing Fillers Confined Between Barrier Nanolayers." Journal of Materials Engineering and Performance: 25 (8): 3275-84.

[5] Mei, Q. S. and Lu, K. 2007. "Melting and Superheating of Crystalline Solids: From Bulk to Nanocrystals." Progress in Materials Science 52 (8): 1175-262.

[6] Kaptay, G., Janczak-Rusch, J., Pigozzi, G. and Jeurgens, L. P. H. 2014. "Theoretical Analysis of Melting Point Depression of Pure Metals in Different Initial Configurations." Journal of Materials Engineering and Performance 23 (5): 1600-7.

[7] Takagi, M. 1954. "Electron-Diffraction Study of Liquid-Solid Transition of Thin Metal Films." Journal of the Physical Society of Japan 9 (3): 359-63.

[8] Wang, Z., Jeurgens, L. P.H., Sigle, W. and Mittemeijer, E. J. 2015. "Observation and Origin of Extraordinary Atomic Mobility at Metal-Semiconductor Interfaces at Low Temperatures." Physical Review Letters 115 (1): 016102.

[9] Chiodi, M., Cancellieri, C., Moszner, F., Andrzejczuk, M., Janczak-Rusch, J. and Jeurgens, L. P. H. 2016. "Massive Ag Migration through Metal/Ceramic Nano-Multilayers: An Interplay between Temperature, Stress-Relaxation and Oxygen-Enhanced Mass Transport." Journal of Materials Chemistry C 4 (22): 4927-38.

[10] Janczak-Rusch, J., Chiodi, M., Cancellieri, C., Moszner, F., Hauert, R. and Pigozzi, G. et al. 2015. "Structural Evolution of Ag-Cu Nano-Alloys Confined Between AlN Nano-Layers upon Fast Heating." Physical Chemistry Chemical Physics 17 (42): 28228-38.

[11] Pigozzi, G., Antušek, A., Janczak-Rusch, J., Parlinska-Wojtan, M., Passerone, D. and Pignedoli, C. A. 2012. "Phase Constitution and Interface Structure of Nano-Sized Ag-Cu/AlN Multilayers: Experiment and $a b$ Initio Modeling." Applied Physics Letters 101 (18): 181602.

[12] Predel, B. 2012. Cu - W (Copper - Tungsten), in B - Ba ... Cu - Zr. Springer Berlin Heidelberg. 270.

[13] Auciello, O., Chevacharoenkul, S., Ameen, M. S. and Duarte, J. 1991. "Controlled Ion Beam Sputter Deposition of $\mathrm{W} / \mathrm{Cu} / \mathrm{W}$ Layered Films for Microelectronic Applications." Journal of Vacuum Science \& Technology A 9 (3): 625-31.

[14] Monclús, M. A., Karlik, M., Callisti, M. and Molina-Aldareguia, J. 2014. "Microstructure and Mechanical Properties of Physical Vapor Deposited $\mathrm{Cu} / \mathrm{W}$ Nanoscale Multilayers: Influence of Layer Thickness and Temperature." Thin Solid Films 571 Part 2 (0): 275-82.

[15] Vüllers, F. T. N. and Spolenak, R. 2015. "From Solid Solutions to Fully Phase Separated Interpenetrating Networks in Sputter Deposited 'Immiscible' W-Cu Thin Films.” Acta Materialia 99: 213-27.

[16] Schweitz, K. O., Rätzke, K., Foord, D., Thomas, P. J., Greer, A. L. and Geisler, H. et al. 2000. "The Microstructural Development of $\mathrm{Ag} / \mathrm{Ni}$ Multilayers during Annealing." Philosophical Magazine A 80 (8): 1867-77.

[17] Chen, K. N., Tan, C. S., Fan, A. and Reif, R. 2004. "Morphology and Bond Strength of Copper Wafer Bonding." Electrochemical and Solid State Letters 7 (1): G14-G16.

[18] Moszner, F., Cancellieri, C., Chiodi, M. and Jeurgens, L. P. H. 2016. "Thermal Stability of $\mathrm{Cu} / \mathrm{W}$ Nano-Multilayers." Acta Materialia 107: 345-53.

[19] Cancellieri, C., Moszner, F., Chiodi, M., Yoon, S., Janczak-Rusch, J. and Jeurgens, L. P. H. 2016. "The impact of thermal treatment on the stress state and evolving microstructure of $\mathrm{Cu} / \mathrm{W}$ nano-multilayers." Journal of Applied Physics 120: 195107. 